\title{
HODGKIN'S DISEASE IN CHILDHOOD
}

\author{
BY \\ DONALD M. DOUGLAS and ALBERT E. CLAIREAUX \\ From the Department of Child Life and Health, University of Edinburgh
}

(RECEIVED FOR PUBLICATION FEBRUARY 27, 1953)

All authorities agree that Hodgkin's disease is rare in childhood and extremely rare under the age of 7 years. The youngest patient in Hodgkin's (1832) original series was a boy of 10 years. Baker and Mann (1939) in a review of 65 cases admitted to Guy's Hospital, London, between the years 1920 and 1937 found seven children $(10 \cdot 8 \%)$ among them, the youngest being 7 years old. Charache (1946) in a review of the literature was able to find eight patients who had developed this disease under the age of $2 \frac{1}{2}$ years. The occurrence of a case of Hodgkin's disease first producing symptoms at the age of 1 year 9 months, and showing pathological features in the lungs not previously recorded in childhood was considered worthy of report.

\section{Case Report}

L.B., a boy aged 1 year 9 months, was admitted to the Royal Hospital for Sick Children, Edinburgh, on November 24, 1950, because of shortness of breath of several days' duration. He had been treated in the hospital a year earlier for infantile eczema and recurrent bronchitis, and both conditions had tended to improve slowly although he had a dry, flexural type of eczema and a dry, irritating cough at the time of his second admission. His respiratory rate was greatly increased to about 120 excursions per minute, but there was surprisingly little distress, no wheezing and no cyanosis; in fact the only abnormality detected on clinical examination of the respiratory system, apart from the tachypnoea, was the presence of a few medium crepitations at the bases of both lungs. Many rubbery nodes were noted in the axillae and groins, varying considerably in size, the largest being as big as a pigeon's egg and situated in the left groin. The edge of the liver was felt four fingerbreadths and the spleen two fingerbreadths below the costal margin (Fig. 1). His temperature was normal. A number of investigations were carried out, but only the more important ones are reported below.

Laboratory Studies. Haemoglobin (Sahli) was 95\%, white cells, 11,600 (neutrophils $59 \%$, lymphocytes $37 \%$, monocytes $3 \%$, eosinophils $1 \%$ ) and platelets 440,000 . The Mantoux test ( 1 in 100 dilution of O.T.) was negative. The serum calcium level was $10.5 \mathrm{mg} . \%$, serum chlorides $646 \mathrm{mg} \%$, the plasma $\mathrm{CO}_{2}$-combining power 60 volumes \%, and a marrow smear was within normal limits. Radiographs of the skull, pelvis and long bones did not reveal any abnormality, but that of the chest showed a fine mottling throughout both lung fields suggestive of miliary tuberculosis or sarcoidosis.

A lymph node was removed from the left inguinal region for histological examination and this suggested the condition to beone of the

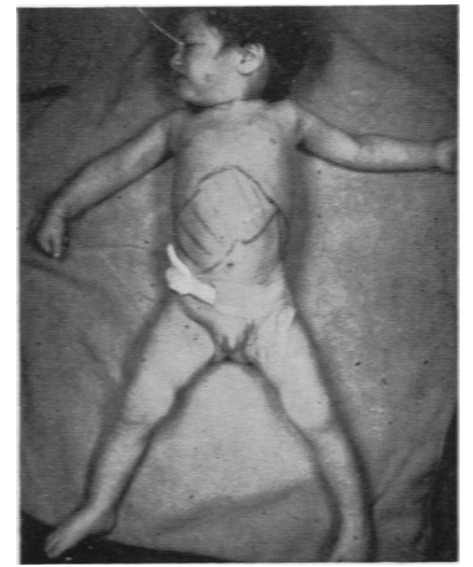

Fig. 1.-L.B., aged 1 year 10 months, showing enlarged lymph nodes and enlarged liver and spleen. malignant reticuloses. The picture was not typically that of Hodgkin's disease, but it was thought to be a variant of that condition.

In spite of treatment with nitrogen mustard (R 151 $25 \mathrm{mg}$. b.d. for 33 days) his weight dropped steadily from $23 \mathrm{lb}$. to 19 lb., his general condition deteriorated, he developed what clinically appeared to be a fully fledged bronchopneumonia which did not respond to oxygen therapy and antibiotics, and he died on January 11, 1951, seven weeks after the onset.

Post-morten Report. The cervical, axillary and inguinal lymph nodes were enlarged; most were approximately $\frac{1}{2} \mathrm{~cm}$. in diameter, firm, and had a homogeneous appearance on section, and a few were considerably larger. The trachea and bronchi were congested and there was a little mucopus in the lower trachea and major bronchi. The lungs were voluminous and the pleural surfaces were studded with emphysematous bullae, the largest being about $\frac{1}{2} \mathrm{~cm}$. in diameter. On section all the lung parenchyma seemed to be honeycombed by small emphysematous cavities and little normal tissue could be seen (Fig. 2). The bronchi stood out sharply from the surrounding tissue and some thin mucopus could be expressed from the cut ends. No evidence of infiltration of lung parenchyma could be found on macroscopic examination. The liver was very large and firm. It was 
pale brown and on section was seen to be heavily studded with whitish deposits which suggested areas of cellular infiltration. Here and there the portal tracts had been severely infiltrated and as a result of biliary obstruction

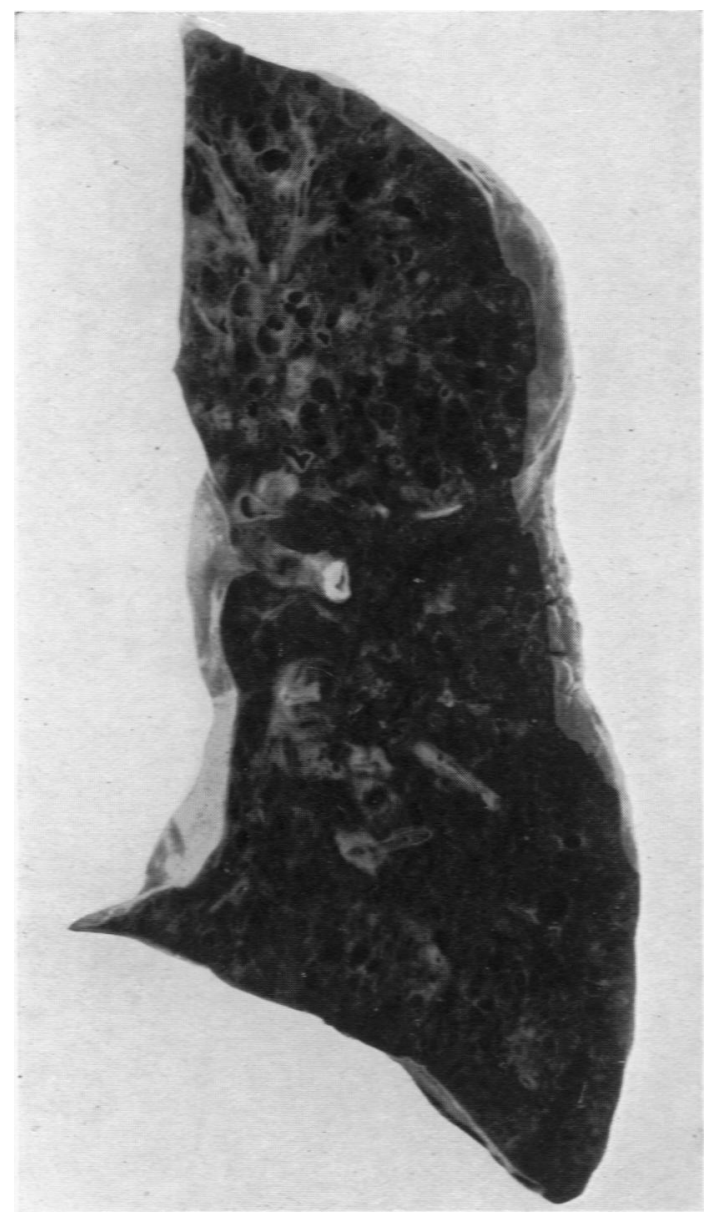

FiG. 2-Section of lung showing gross emphysema.

the infiltrated areas were locally stained with bile. The spleen was moderately enlarged and very firm. The capsule was wrinkled and on section the Malpighian bodies were very prominent. There was no obvious infiltration on macroscopical examination. Nothing of pathological interest was found in the brain, bowel, kidneys or etsewhere.

Histological Report. The pleura was healthy. The lungs showed tremendous emphysematous change. Many alveolar walls were broken down to form large air spaces. The bronchi were also affected and varying degrees of pathological change had occurred. In the most severely affected bronchi there was complete disorganization of the entire wall (Fig. 3). The epithelium had been stripped and the wall was replaced by Hodgkin tissue consisting of numerous reticulum cells with vesicular nuclei and pale acidophil cytoplasm. The cellular infiltration was remarkably isomorphic and no bizarre multinucleated forms of reticulum cells were seen. Here and there foci of eosinophil leucocytes were seen. The infiltrating tissue had spread longitudinally along the bronchovascular sheaths and had involved the adventitia of the pulmonary vessels. The arteries were involved slightly and only the adventitial coat was affected. The alveoli neighbouring the sites of bronchovascular infiltration showed interstitial infiltration with reticulum cells and cosinophils. In some areas the involvement of the peribronchial alveoli was very pronounced, their lumen being greatly reduced, and they appeared to be lined by prominent cuboidal cells thus giving a glandular appearance. Other bronchi had an almost intact epithelium but polypoid masses of Hodgkin's tissue were growing into the lumen (Fig. 4). The outer walls of these bronchi were also infiltrated. Still other bronchi showed squamous metaplasia of their lining epithelium and their lumen contained an acute inflammatory exudate with numerous polymorphonuclear leucocytes and cellular debris. This was probably the result of an acute terminal infection. The

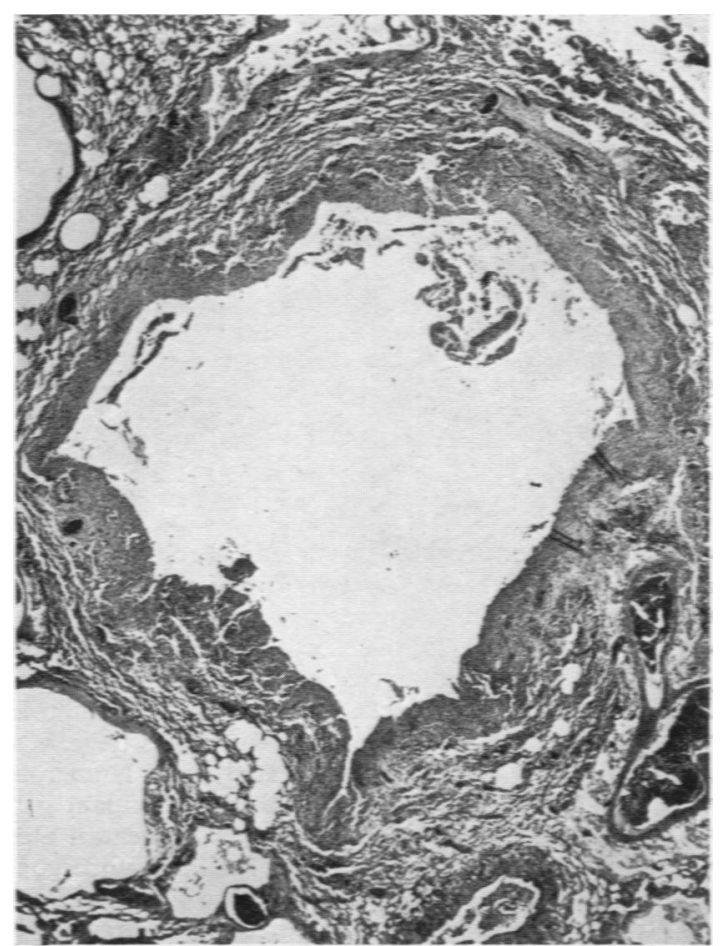

Fig. 3.-Large bronchus $\times 12$ (hacmatoxylin and cosin). The bronchial wall has been replaced by Hodgkin tissue.

appearances in the lungs were those of Hodgkin's disease of the bronchovascular infiltrative type. The results of this extensive bronchovascular, interstitial and intrabronchial infiltration had been a chronic partial obstruc- 
tion of the air passages and the development of severe emphysema (Fig. 5).

The capsule of the liver was normal. The liver cells were healthy and the lobular pattern was preserved. The portal tracts showed moderate infiltration with reticulum cells and eosinophil cells. There was a considerable increase in the fibrous tissue of the portal tracts and fibroblastic activity was still present. The bile ducts were healthy. The portal tracts were extending out into the parenchyma and there was proliferation of small bile

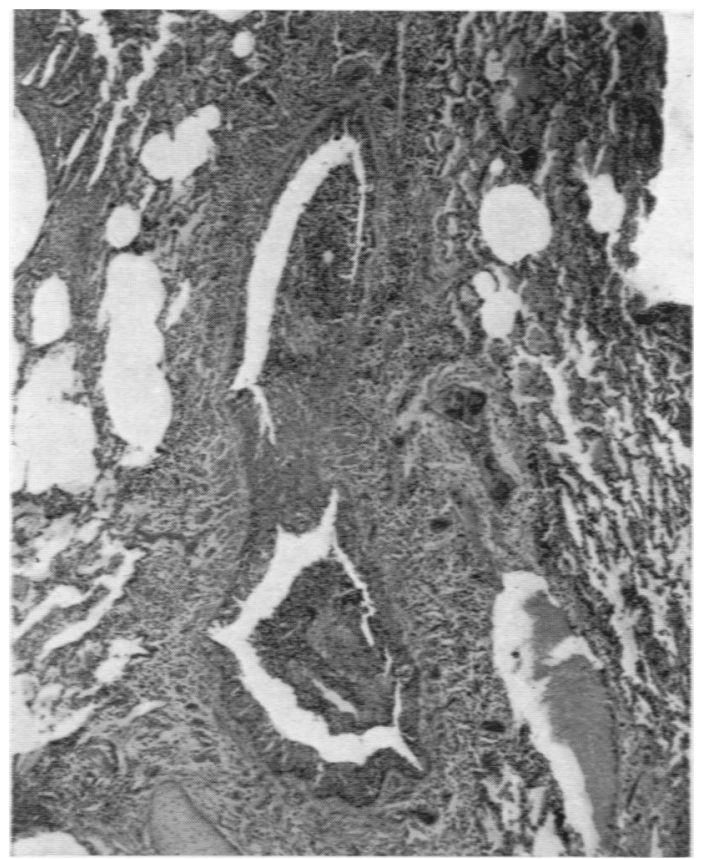

Fig. 4.-Lung $\times 35$ (hacmatoxylin and cosin). Hodghin tissue is growing into the bronchial lumen causing partial obstruction.

ducts at the periphery of the larger portal tracts. The appearance was that of an early cirrhosis, with fibrous tissue proliferation a more prominent feature than cellular infiltration. In one section there was a large portal tract with greatly increased fibrous tissue and proliferation of small bile ducts. In the centre of the fibrous tissue was a large circular area of Hodgkin's tissue surrounded by a capsule of fibrous tissue. Numerous reticulum cells with pyknotic nuclei and abundant pale acidophil cytoplasm were present near the central area which was necrotic. The lesion might have undergone necrosis as a result of the use of nitrogen mustard but had been too large to undergo replacement fibrosis.

In the spleen the pulp was congested. The Malpighian bodies showed reticulum cell proliferation in their germinal centres but there was surprisingly little upset in the architecture of the organ.

The capsule of an inguinal lymph node was thickened. The structure was partly replaced by Hodgkin tissue. This consisted of a proliferative lesion of reticulum cells with numerous giant cells of the Greenfield type and some eosinophil cells (Fig. 6). There were small areas of necrosis and a generalized increase in the fibrous tissue

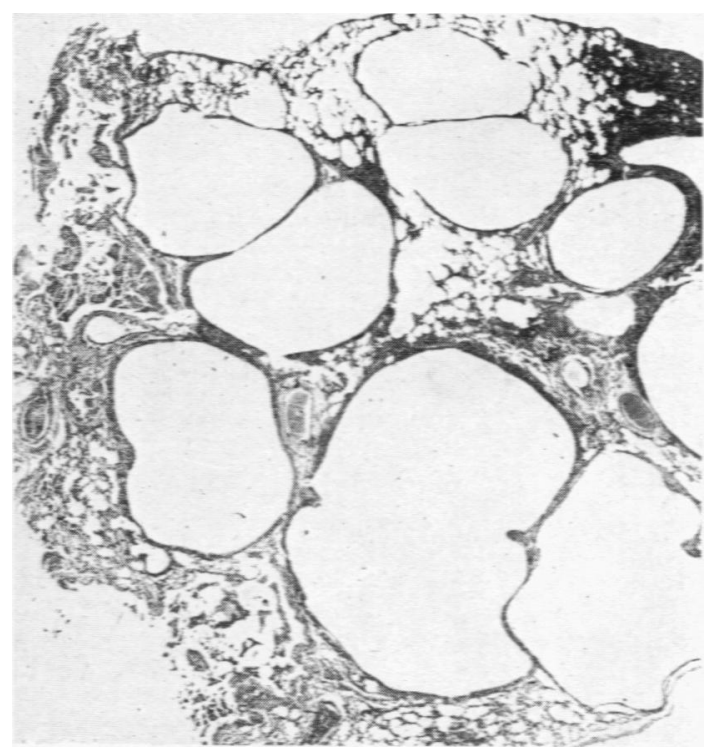

FiG. 5. - Lung $\times 8$ (hecmatoxylin and $\operatorname{cosin}$ ). Honeycomb appearance of lung resulting from gross emphysema.

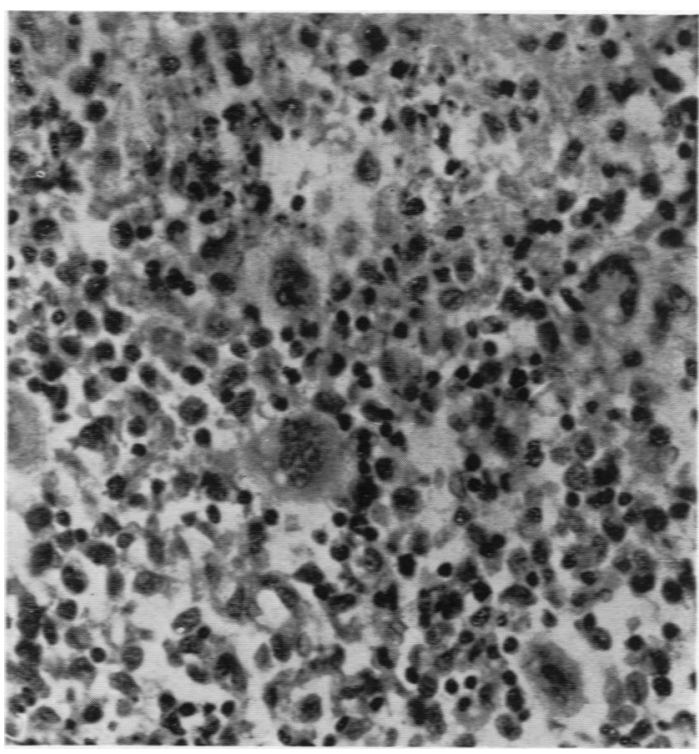

FiG. 6-Lymph node $\times 350$ (azoeosin). Numerous giant cells and cosinophil keucocytes are seen.

framework. Similar changes were found in mediastinal, mesenteric, Peyer's patches and other lymph nodes. 
The kidneys, pancreas and heart showed nothing of pathological interest.

\section{Discuscion}

The reticuloses are an important group of disorders in infancy and childhood. They comprise the leukaemias, Hodgkin's disease, the lipoidoses, the non-lipoid reticuloses such as Letterer-Siwe disease and familial haemophagocytic reticulosis, and the reticulosarcomata. The leukaemias and the lipoidoses are relatively easily differentiated from Hodgkin's disease but the other forms may cause some difficulty, especially in infants. Letterer-Siwe disease, haemophagocytic reticulosis and Hodgkin's disease may all present with generalized painless enlargement of the superficial lymph nodes and intermittent fever. In both Letterer-Siwe disease and in the intrapulmonary form of Hodgkin's disease $x$-ray examination of the chest shows a fine mottling reminiscent of miliary tuberculosis or sarcoidosis. The reticulosarcomata are generally confined to one group of lymph nodes but affection of the cervical group is common both in Hodgkin's disease and reticulosarcoma.

Final diagnosis rests with the histological findings in a biopsy specimen. Cervical nodes are more suitable than inguinal nodes for this type of examination on account of the frequency of non-specific changes in the latter.

Intrathoracic lesions are common in Hodgkin's disease, and at necropsy the mediastinal lymph nodes are almost invariably involved. This glandular enlargement may cause collapse of the lung from pressure effects or the disease process may extend from the hilar glands into the lung parenchyma directly or via the peribronchial and perivascular lymphatics. A more rare type of lesion is a granulomatous bronchitis and peribronchitis as was seen in our case. This type of lesion has been described by Moolten (1934) in an adolescent but does not seem to have been reported previously in an infant. In this form the bronchi are replaced by Hodgkin tissue composed of reticulum cells, giant cells, eosinophils and lymphocytes. The disease process spreads along the bronchovascular spaces, papilliform outgrowths of Hodgkin tissue project into the bronchial lumen and tend to cause obstruction of the air passages and gross emphysema may develop. This occurred in the present case. Hodgkin pneumonia caused by infiltration of Hodgkin tissue throughout the lung alveoli has also been described (Moolten, 1934). Occasionally plaques of Hodgkin tissue are found on the visceral pleura and a serosanguineous effusion develops. Schwind and Hyde (1942) have reported the occurrence of Hodgkin's disease in an infant. In their case there was a plaque of Hodgkin tissue on the surface of both lungs and Hodgkin tissue was also found in the lung parenchyma. The abdominal organs and retroperitoneal lymph nodes were also extensively involved. Schwind and Hyde were able to find only eight previously reported causes of Hodgkin's disease in infants. Of these eight cases, three were congenital, three showed involvement of the cervical glands and two of the thymus.

\section{Summary}

A case of Hodgkin's disease occurring in a child of 1 year and 9 months is described. Granulomatous bronchitis and peribronchitis was found at necropsy. This rare lesion has not previously been reported in childhood.

We are grateful to Professor J. L. Henderson for giving his permission to publish this case.

\section{Rerizences}

Baker, C. and Mann, W. N. (1939). Guy's Hosp. Rep., 89, 83. Charache, H. (1946). N.Y. St. J. Med, 46, 507.

Hod-kin, T. (1832). Med.-chir. Trass., 17, 68.

Mootien, S. E (1934). Amer. J. Cancer, 21, 253.

Schwind, J. L. and Hyde, G. M. (1942). J. Pediat., 21, 238. 